\title{
Color Stability and Translucency of Two CAD-CAM Restorative Materials Subjected To Mechanical Polishing, Staining, and Prophylactic Paste Polishing Procedures
}

\section{Mekanik Cilalama, Renklenme ve Profilaktik Cilalama Sonrası BDT/BDÜ Materyallerinin Renk Değişimi ve Translusensi Değerlerinin İncelenmesi}

\author{
Bengisu YILDIRIM ${ }^{1}$, Duygu RECEN ${ }^{2}$ \\ ${ }^{1}$ Uşak Üniversitesi Diş Hekimliği Fakültesi, Protetik Diş Tedavisi Anabilim Dalı, Uşak \\ ${ }^{2}$ Izmir Demokrasi Üniversitesi Diş Hekimliği Fakültesi, Restoratif Diş Tedavisi Anabilim Dalı, İzmir
}

Atıf/Citation: Yıldırım, B., Recen, D., (2021). Mekanik Cilalama, Renklenme ve Profilaktik Cilalama Sonrası BDT/BDÜ Materyallerinin Renk Değişimi ve Translusensi Değerlerinin İncelenmesi. Ege Üniversitesi Diş Hekimliği Fakültesi Dergisi, 42(1), 1-8.

Öz

Giriş ve Amaç: Bu çalışmanın amacı, mekanik polisaj, kahve ile renklendirme ve profilaktik polisaj prosedürlerine tabi tutulduktan sonra bilgisayar destekli tasarım ve bilgisayar destekli (BDT/BDÜ) bloklardan elde edilen örneklerin translusensi ve renk değişimini değerlendirmektir.

Yöntem ve Gerecler: Her iki bloktan (Cerasmart A2-HT; GC, Initial-LRF, A2-HT: GC) toplam 26 adet örnek (n= 13) elde edildi. Örneklerin renk değişimi ve translusensi değerleri mekanik cilalama, kahve ile renklendirme ve profilaktik cilalama prosedürlerine tabi tutulduktan sonra spektrofotometre ile ölçüldü. Veriler Shapiro-Wilk normallik testi ile analiz edildi. Translusensi ve renk değişim değerleri Friedman testi ile istatistiksel olarak değerlendirildi. Translusensi ve renk değişimi açısından Cerasmart ve Initial-LRF arasındaki istatistiksel farkı belirlemek için ise Mann Whitney-U testi kullanıldı $(\alpha=.05)$.

Bulgular: Cerasmart ilk ölçümde ve mekanik parlatma sonrası Initial-LRF'e göre istatiksel olarak anlamlı derecede daha translusent bulunmuştur $(p<0.05)$. Her iki grupta kahve istatiksel olarak anlamlı derecede fazla renk değişimine neden olmuştur. Profilaktik cilama sonrasında ise istatiksel olarak anlamlı derecede renk değişimi olmuştur $(p<0.05)$.

Tartışma ve Sonuç: Cerasmart, kahvede Initial-LRF'e göre daha fazla renklenmiştir. Kahve her iki materyalin translusensi değerlerini düşürmüştür. Renklenen seramik materyallerinin profilaktik cilanlanması klinik uygulama için önerilebilir bir yöntemdir.

Anahtar Kelimeler: Bilgisayar destekli tasarım, Seramikler, Diş protezini renklendirme, Dental Estetik, Spektrofotometri

\section{ABSTRACT}

Introduction: The aim of this study is to evaluate the translucency and color change of two computer-aided design and computeraided manufacturing (CAD/CAM) blocks after subjected to mechanic polishing, coffee staining, and prophylactic paste polishing procedures.

Methods: 26 specimens ( $n=13$ ) were obtained from each CAD/CAM block (Cerasmart A2-HT; GC, Initial-LRF, A2-HT: GC). Color change values were evaluated after subjected to mechanic polishing, coffee staining, and prophylactic polishing procedures. Data were analyzed by a Shapiro-Wilk normality test and the translucency and color change values were evaluated statistically with Friedman test. Mann Whitney- $U$ test was used to determine the statistical significance between the Cerasmart and Initial-LRF in terms of translucency and color change ( $\alpha=.05)$.

Results: For baseline measurements and after mechanic polishing measurement, the mean translucency value of the Cerasmart was significantly higher than Initial-LRF $(p<0.05)$. In Cerasmart and Initial-LRF groups, coffee storage significantly increased the color change value, polishing with a prophylactic paste significantly decreased the color change value $(p<0.05)$.

Discussion and Conclusion: Cerasmart, showed higher discoloration rate in coffee than Initial-LRF, and the translucency values of both Cerasmart and Initial-LRF specimens stored in the coffee solution decreased. Also, polishing with a prophylactic paste can be recommended.

Keywords: Computer-aided design, Ceramics, Dental Prosthesis Coloring, Dental Esthetics, Spectrophotometry 


\section{INTRODUCTION}

It is possible to produce restorations with different contents of materials using computer-aided design and computer-aided manufacturing (CAD-CAM) technology. Both ceramic and hybrid restorative materials are popular alternatives for the fabrication of tooth-colored restorations. An esthetic restoration should mimic the optical characteristics of enamel and dentin to match with the adjacent tooth. ${ }^{1}$ Leucite reinforced feldspar ceramic blocks present esthetic by combining traditional fedspathic ceramic and leucite ceramic as similar optical properties as enamel and dentin. Leucite reinforced feldspar material, comes as deep chroma, high fluorescence, opalescence, and/or high translucency. ${ }^{2}$ This material gains increased flexural strength and offers resistance against possible crack formations with the addition of leucite crystals and glass matrix. ${ }^{2}$

As an alternative to glass-ceramic blocks, hybrid materials have been introduced by combining the advantageous properties of ceramic and composite resins. Hybrid-ceramics offer better mechanical and esthetic properties than composite resins, including higher fracture resistance and better optical properties. ${ }^{3}$ Moreover, their abrasiveness are higher than ceramics. ${ }^{4}$ These materials have polymeric matrix reinforced by nano-hybrid fillers and offer a wide range of indications. ${ }^{5}$

With the developing technology, esthetic expectations of the patients increased and color stability has become as important as mechanical success on the survival of restorative materials. ${ }^{6}$ It was reported that aging, polishing, staining by the beverages, and prophylactic polishing pastes may affect the optical properties and the color stability of restorations. ${ }^{3,7-9}$

Even if the perfect color match obtained, restorative materials can change over time depending on the oral environment. Temperature differences, humidity, consuming food\&drinks, and smoking that can be linked to discoloration. ${ }^{7}$ Chemical agents pass-through by micro-cracks on the restoration surface and leads restoration to faster deterioration. Degradation of polymer matrix usually results in color change which affects the esthetic outcome. ${ }^{10}$

Finishing and polishing procedures not only make the surface of the restoration smooth and glossy but also alter the light-reflection. Surface smoothness is required for protecting the surface of the restoration from stain. ${ }^{8}$

Leucite reinforced feldspar ceramics offers a smooth surface right after milling and can be easily polished by conventional mechanical tools with excellent gloss which is an effective feature against discoloration. ${ }^{2}$ When compared to composite resins, hybrid-ceramics are thought to be more resistant to discoloration because of the enhanced polymerization process. However, color changes associated with water sorption still occur. ${ }^{8}$ In many studies coffee and red wine have been used as staining solutions because of their high potential for staining. ${ }^{3,9,10}$ Sarkaya et al. ${ }^{9}$ also mentioned that coffee is the most staining solution on hybrid-ceramic and resin nano-ceramic surfaces. Therefore, for long-term use of esthetic restorations, patients should regularly receive a professional dental cleaning. During follow-up times, all teeth and restorations should undergo a polish with a prophylactic polishing paste which removes discoloration. Impacts on the discoloration rates may change depending both on the material type and the type of the paste. ${ }^{11}$

Commission Internationale de l' Eclairage (CIE) Lab color coordinates are representative parameters about the color. $L^{*}$ represents the lightness of the object, $\mathrm{a}^{*}$ represents greenness $(+)$-redness $(-)$ and $\mathrm{b}^{*}$ represents yellowness (+)-blueness $(-)$. The color parameters $\left(\mathrm{L}^{*}, \mathrm{a}^{*}, \mathrm{~b}^{*}\right)$ of restorative materials can be measured from a reflectance or transmittance. ${ }^{12}$ In 2001, the CIEDE2000 formula was improved for calculating the differences between two shades. In a previous study, this formula found to be more successful than CIELab formula while perceiving differences. ${ }^{6}$

The translucency of a restorative material plays an important role in the esthetic outcome and can be measured with the translucency parameter (TP) and the contrast ratio (CR). TP can be derived from the color difference between the black and white background measurements ${ }^{13,14}$ while $\mathrm{CR}$ is the ratio of the reflectance. $^{1,15}$

To the best of the authors' knowledge, there was not any study evaluating the TP and color change of Initial LRF, leucite reinforced feldspar ceramic, which is a novel material. Besides, there were inconsistent results regarding the translucency and color change after polishing, staining, and polishing with prophylaxis paste procedures with CAD-CAM ceramics. ${ }^{3,5-8}$

Therefore, the aim of this study was to evaluate the optical properties of two CAD-CAM restorative materials (leucite reinforced feldspar ceramic and hybrid-ceramic) after polishing, staining, and prophylactic paste polishing procedures, respectively. The first null hypothesis was that the type of material would not affect the color stainability and translucency. The second null hypothesis was that mechanical polishing, coffee storage, and polishing with prophylactic paste would not affect the color stainability and translucency of the materials.

\section{MATERIALS AND METHODS}

A power analysis was performed and at least 13 specimens were found to be enough per group at the 0.05 level with $95 \%$ power.

Two types of CAD-CAM blocks (Table 1); hybridceramic CAD-CAM block (Cerasmart A2-HT; GC, Tokyo, Japan) and a leucite reinforced feldspar ceramic 
CAD-CAM blocks (Initial LRF A2-HT; GC, Tokyo, Japan), were sectioned by a low-speed diamond saw (Microcut; Metkon Instruments, Bursa, Turkey) under continuous water cooling. A total of 26 rectangular specimens $(n=13)$ at a thickness of $(0.8 \pm 0.01 \mathrm{~mm})$ and a dimension of $(7 \times 12 \mathrm{~mm})$ were obtained from each ceramic brand. It was planned to mimic an anterior restoration. All specimens were ultrasonically cleaned in distilled water for $10 \mathrm{~min}$. One side of each specimen was polished with 600-, 800-, 1000-, 1200-grit silicon carbide paper (Water Proof SiC Paper; Struers, USA) under continuous water cooling by a polishing machine (LaboPol-25; Struers, USA). The thickness of each specimen was measured and controlled with a digital micrometer (Mitutoyo Corp; Tokyo, Japan). All specimens were numbered from 1 to 13 to standardize the measurement order.

Table 1: CAD-CAM materials used in this study.

\begin{tabular}{|l|l|l|l|l|}
\hline $\begin{array}{l}\text { CAD/CAM } \\
\text { Material }\end{array}$ & Shade & Type of material & Compounds & Manufacturer \\
\hline Cerasmart & A2/HT & Hybrid-ceramic & $\begin{array}{l}29 \% \text { Bis-MEPP, UDMA, DMA } \\
71 \% \text { Silica }(20 \text { nm), barium glass }(300 ~ n m)\end{array}$ & GC, Tokyo, Japan \\
\hline Initial LRF & A2/HT & $\begin{array}{l}\text { Leucite reinforced } \\
\text { feldspar ceramic }\end{array}$ & $\begin{array}{l}70-80 \text { vol\%. Crystalline phase } \\
(1.5-3 \mu \mathrm{m} \text { leucite cystals })\end{array}$ & GC, Tokyo, Japan \\
\hline
\end{tabular}

The baseline measurements (T0) were performed on black, grey, and white backgrounds with a digital spectrophotometer (Vita Easyshade V; Vita Zahnfabrik, Bad Sackingen, Germany). Mean color coordinates were recorded according to the CIEDE2000 $\left(\Delta \mathrm{E}_{00}\right)$ color system after 3 repeated measurements. Before each specimens' measurement, the spectrophotometer device was calibrated. All measurements were done at the center of the specimens by the same investigator. Values on grey backgrounds used for color change after each procedure. ${ }^{14}$ Values on black $\left.\left(\mathrm{L}^{*} \mathrm{~b}, \mathrm{a}{ }_{\mathrm{b}}, \mathrm{b}_{\mathrm{b}}\right)\right)$ and white $\left(\mathrm{L}^{*}{ }_{\mathrm{w}}, \mathrm{a}^{*}{ }_{\mathrm{w}}, \mathrm{b}^{*}{ }_{\mathrm{w}}\right)$ backgrounds were used to evaluate translucency parameter (TP), and the following formula was used to calculate $\mathrm{TP}_{00}$ value: ${ }^{14}$

$$
T P 00=\sqrt{\left(\frac{\Delta L^{\prime}}{K_{L} S_{L}}\right)^{2}+\left(\frac{\Delta C^{\prime}}{K_{C} S_{C}}\right)^{2}+\left(\frac{\Delta H^{\prime}}{K_{H} S_{H}}\right)^{2}+R_{T}\left(\frac{\Delta C^{\prime}}{K_{C} S_{C}}\right)\left(\frac{\Delta H^{\prime}}{K_{H} S_{H}}\right)},
$$

In this formula, where $\Delta \mathrm{L}^{\prime}, \Delta \mathrm{C}^{\prime}$, and $\Delta \mathrm{H}^{\prime}$ represent the differences in lightness, chroma, and hue between the black and white measurements' color coordinates. The RT is the interaction between the chroma and hue differences in the blue region. SL, SC, and SH are weighting functions and are used to adjust the total color difference. $\mathrm{KL}, \mathrm{KC}$, and $\mathrm{KH}$ are parametric factors and correction terms for experimental conditions. RT, KL, KC, and $\mathrm{KH}$ were set as 1 in the formula. ${ }^{14}$

After the baseline measurements, the Cerasmart specimens were mechanically polished at 10,000 rpm for $30 \mathrm{~s}$ with a fine polishing system (OptraGloss HP,
OptraGloss; Ivoclar Vivadent, Schaan, Liechtenstein). The LRF specimens were first pre-polished with a coarse polishing system (OptraGloss PP, OptraGloss; Ivoclar Vivadent, Schaan, Liechtenstein), then polished with a fine polishing system (OptraGloss HP, OptraGloss; Schaan, Ivoclar Vivadent, Liechtenstein) at $10,000 \mathrm{rpm}$ for $30 \mathrm{~s}$. After polishing, the second measurements (T1) were performed with a spectrophotometer with the same protocol of baseline measurements, and the $\mathrm{TP}_{00}$ values were calculated and recorded. ${ }^{14}$ Values on grey backgrounds used for $\Delta \mathrm{E}_{00}$ calculation. The following formula was used to calculate $\Delta \mathrm{E}_{00}$ value: ${ }^{14}$

$$
\Delta E_{00}=\sqrt{\left(\frac{\Delta L^{\prime}}{K_{L} S_{L}}\right)^{2}+\left(\frac{\Delta C^{\prime}}{K_{C} S_{C}}\right)^{2}+\left(\frac{\Delta H^{\prime}}{K_{H} S_{H}}\right)^{2}+R_{T}\left(\frac{\Delta C^{\prime}}{K_{C} S_{C}}\right)\left(\frac{\Delta H^{\prime}}{K_{H} S_{H}}\right)},
$$

In this formula, where $\Delta \mathrm{L}^{\prime}, \Delta \mathrm{C}^{\prime}$, and $\Delta \mathrm{H}^{\prime}$ represent the differences in lightness, chroma, and hue between the first and second measurements' color coordinates. The RT is the interaction between the chroma and hue differences in the blue region. SL, SC, and SH are weighting functions and are used to adjust the total color difference. $\mathrm{KL}, \mathrm{KC}$, and $\mathrm{KH}$ are parametric factors and correction terms for experimental conditions. RT, KL, KC, and $\mathrm{KH}$ were set as 1 in the formula. ${ }^{14}$
Afterward the specimens were stored in a coffee solution for one week at $37^{\circ} \mathrm{C}$. To prepare the coffee solution; 7.5 g of coffee (Nescafé Gold, Nestlé; Vevey, Switzerland) were dissolved in $500 \mathrm{~mL}$ hot water. The solution was refreshed each day. ${ }^{16,17}$ After coffee storage, specimens were cleaned with water spray and then air-dried before third measurements (T2). The measurements were performed with a spectrophotometer with the same protocol of baseline measurements. The $\mathrm{TP}_{00}$ and $\Delta \mathrm{E}_{00}$ were calculated and recorded. 
After 1-week coffee storage, stained surfaces of the two groups were polished with a paste, Proxyt Fine (Ivoclar Vivadent; Schaan, Liechenstein), using rubber cups at a speed of $10,000 \mathrm{rpm}$ for $1 \mathrm{~min}$. Then, the specimens were cleaned with water spray and air-dried. The fourth measurements (T3) were performed again with the same protocol. The $\mathrm{TP}_{00}$ and $\Delta \mathrm{E}_{00}$ were calculated and recorded.

\section{Statistical Analysis}

For statistical analysis a software program, SPSS v21.0 (IBM Corp, Armonk, NY, U.S.A.), was used. Shapiro-Wilk normality test was used to test the distribution $(p<0.05)$. The data were not distributed normally. Therefore, the $\mathrm{TP}_{00}$ and $\Delta \mathrm{E}_{00}$ values were evaluated statistically with the Friedman test. Mann Whitney-U test was used to determine the statistical significance between the CER and LRF groups in terms of $\Delta \mathrm{E}_{00}$ and $\mathrm{TP}_{00}$ values $(\alpha=0.05)$.

\section{RESULTS}

The mean $\mathrm{TP}_{00}$ values of CER and LRF groups after each procedure were presented in Table 2. No significant difference was found among the procedures in terms of $\mathrm{TP}_{00}$ for both materials $(p>0.05)$ (Table 2 and Figure 1).

Table 2: $\mathrm{TP}_{00}$ values of the hybrid-ceramic and leucite reinforced feldspar ceramic materials after different procedures.

\begin{tabular}{|l|l|l|l|l|}
\hline \multirow{2}{*}{$\mathrm{TP}_{00}$} & Baseline & Mechanical polishing & $\begin{array}{l}\text { Coffee storage } \\
\text { (One week) }\end{array}$ & $\begin{array}{l}\text { Polishing with a } \\
\text { prophylactic paste }\end{array}$ \\
\cline { 2 - 5 } & Mean \pm Std.dev & Mean \pm Std.dev & Mean \pm Std.dev & Mean \pm Std.dev \\
\cline { 1 - 4 } Material & $16.9 \pm 1.5^{\mathrm{Aa}}$ & $16.2 \pm 1.0^{\mathrm{Aa}}$ & $14.9 \pm 1.9^{\mathrm{Aa}}$ & $15.7 \pm 1.6^{\mathrm{Aa}}$ \\
\cline { 1 - 4 } & $14.1 \pm 0.5^{\mathrm{Ba}}$ & $14.6 \pm 0.7^{\mathrm{Ba}}$ & $13.7 \pm 1.8^{\mathrm{Aa}}$ & $14.4 \pm 1.1^{\mathrm{Aa}}$ \\
\hline
\end{tabular}

The same superscript lowercase letters represent no significant difference in rows at the 0.05 level according to Friedman test. The same superscript capital letters indicate no significant difference in columns at the 0.05 level according to Mann-Whitney U test. CER, Cerasmart; LFR, Initial LRF; TP, Translucency Parameter

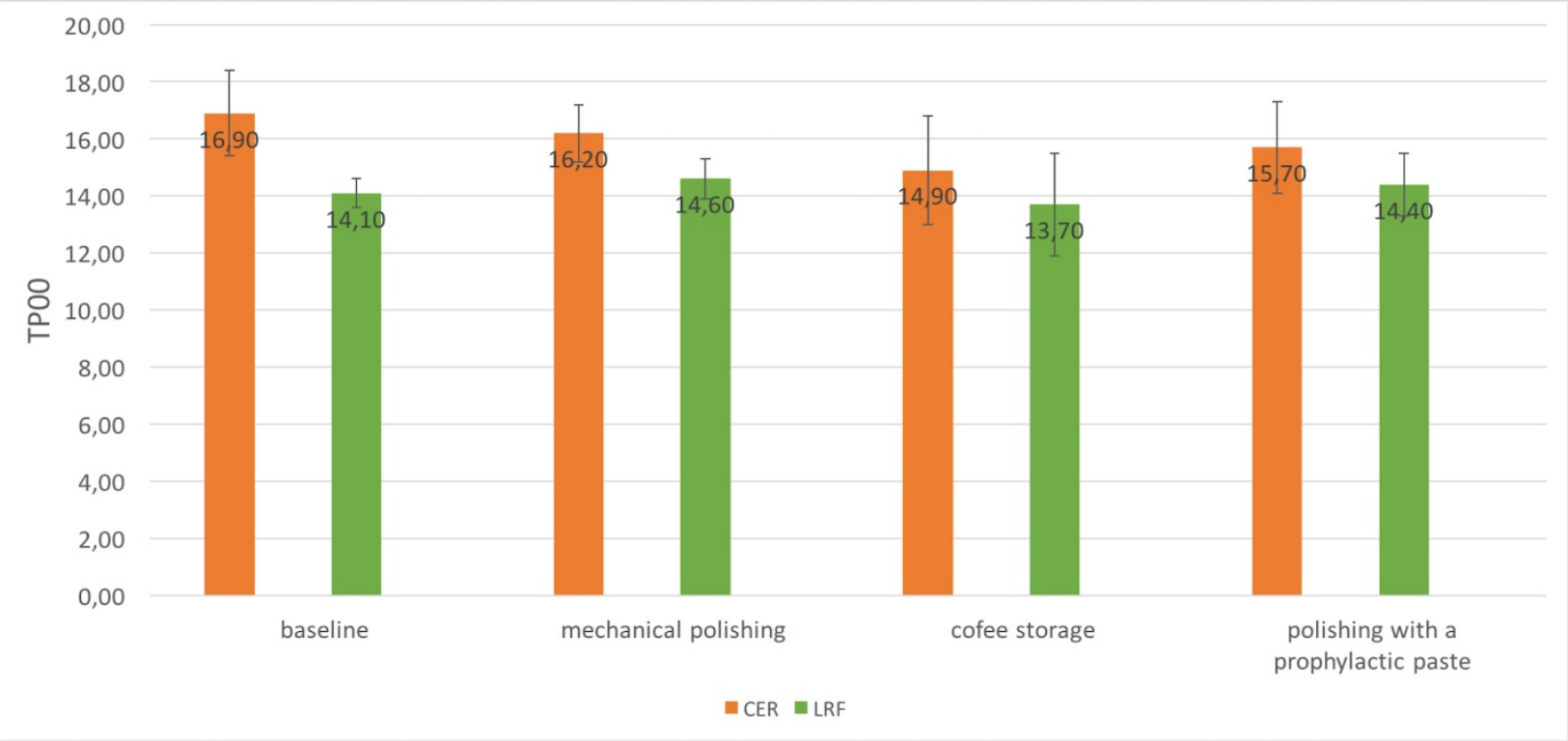

Figure 1: Mean $\mathrm{TP}_{00}$ values of groups according to the procedures.

CER, Cerasmart; LFR, Initial LRF; TP, Translucency Parameter

For baseline measurements and after mechanical polishing measurement, the mean $\mathrm{TP}_{00}$ value of the CER (baseline measurement, 16.9 \pm 1.5 ; mechanical polishing measurement, 16.2 \pm 1.0 ) was significantly higher than LRF (baseline measurement, 14.1 \pm 0.5 ; mechanical polishing measurement, 14.6 \pm 0.7$)(p<0.001)$ (Table 2).

The mean $\Delta \mathrm{E}_{00}$ values of CER and LRF groups after each procedure were presented in Table 3. A significant difference was found among the procedures in terms of $\Delta \mathrm{E}_{00}$ for both materials $(p<0.001)$. In the CER group, coffee storage significantly increased the $\Delta \mathrm{E}_{00}$ value (3.9 \pm 0.3$)$, while polishing with a prophylactic paste significantly decreased the $\Delta \mathrm{E}_{00}$ value $(1.4 \pm 0.2)$. However, the difference between mechanical polishing and polishing with a prophylactic paste was not statistically significant $(p>0.05)$. In the LRF group, 
coffee storage significantly increased the $\Delta \mathrm{E}_{00}$ value (3.5 \pm 0.4$)$, while polishing with a prophylactic paste significantly decreased the $\Delta \mathrm{E}_{00}$ value $(0.4 \pm 0.04)$. However, the difference between mechanical polishing and polishing with a prophylactic paste was not statistically significant ( $p>0.05$ ) (Table 3 and Figure 2).
The mean $\Delta \mathrm{E}_{00}$ value of the CER and LRF was similar after mechanical polishing $(p>0.05)$. The CER group showed a statistically higher $\Delta \mathrm{E}_{00}$ value than the LRF group after coffee storage. CER group showed a statistically higher $\Delta \mathrm{E}_{00}$ value than the LRF group after polishing with a prophylactic paste (Table 3 ).

Table 3: $\Delta \mathrm{E}_{00}$ values of the hybrid-ceramic and leucite reinforced feldspar ceramic materials after different procedures

\begin{tabular}{|l|l|l|l|}
\hline \multirow{2}{*}{$\Delta \mathrm{E}_{00}$} & Mechanical polishing & $\begin{array}{l}\text { Coffee storage } \\
\text { (One week) }\end{array}$ & $\begin{array}{l}\text { Polishing with a } \\
\text { prophylactic paste }\end{array}$ \\
\cline { 2 - 4 } & Mean \pm Std.dev & Mean \pm Std.dev & Mean \pm Std.dev \\
\hline Material & \multirow{2}{*}{$0.9 \pm 0.8^{\mathrm{Aa}}$} & $3.9 \pm 0.3^{\mathrm{Bb}}$ & $1.4 \pm 0.2^{\mathrm{Dac}}$ \\
\hline CER & $0.3 \pm 0.07^{\mathrm{Aa}}$ & $3.5 \pm 0.4^{\mathrm{Cb}}$ & $0.4 \pm 0.04^{\mathrm{Eac}}$ \\
\hline LRF &
\end{tabular}

The same superscript lowercase letters represent no significant difference in rows at the 0.05 level according to Friedman test. The same superscript capital letters indicate no significant difference in columns at the 0.05 level according to Mann-Whitney U test.

CER, Cerasmart; LFR, Initial LRF; $\Delta \mathrm{E}_{00}$, Color Change

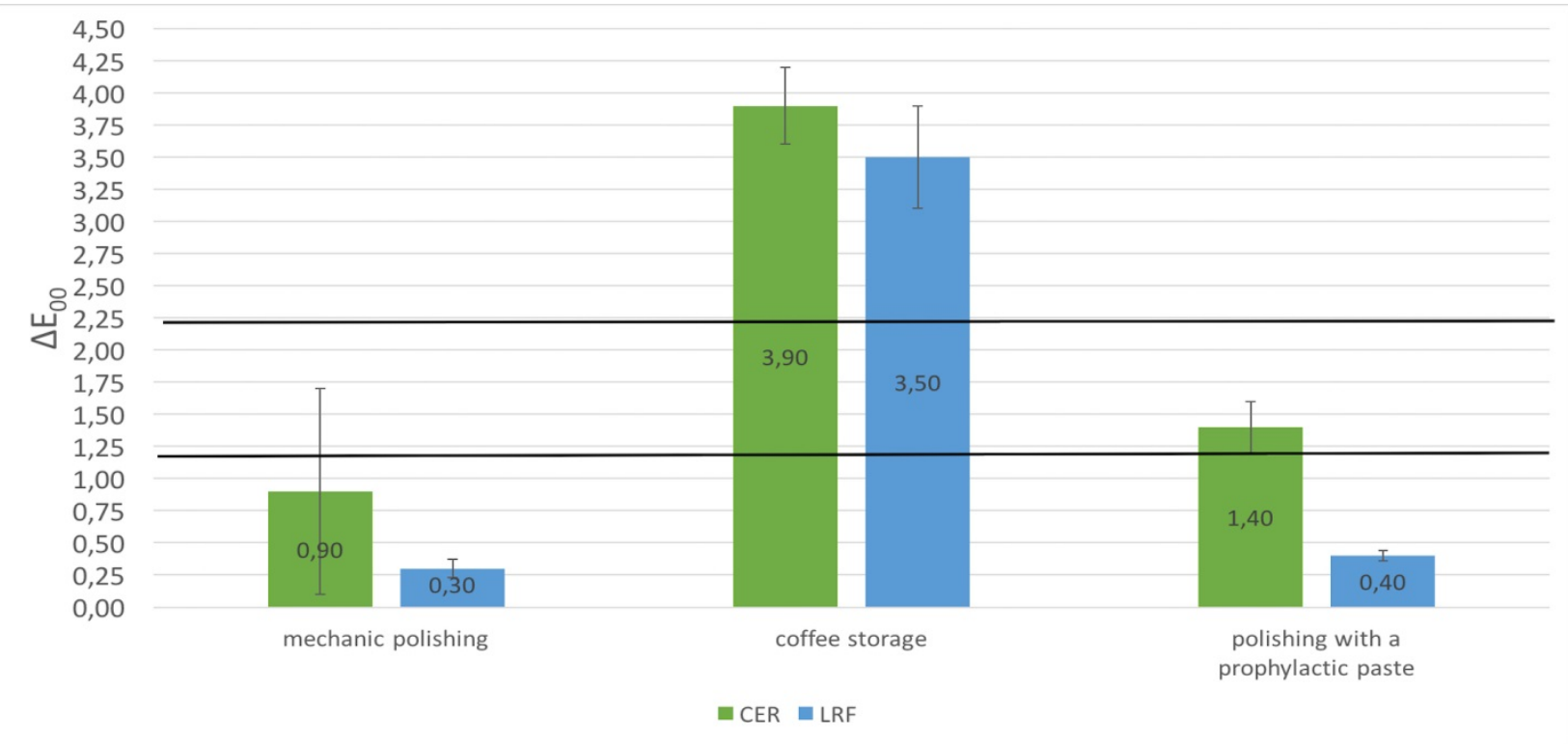

Figure 2: Mean $\Delta \mathrm{E}_{00}$ values of groups according to the procedures.

The $\Delta \mathrm{E}_{00}=2.25$ is the threshold of clinically acceptable color difference and $\Delta \mathrm{E}_{00}=1.30$ is the threshold of the perceptibility of color difference.

\section{DISCUSSION}

The first null hypothesis was partly accepted since material type had a significant effect on the color changes. However, it did not affect the translucency. The second hypothesis was partly accepted because coffee storage and mechanical polishing or polishing with prophylactic paste affected the color changes although they did not affect the translucency.

According to a study by Celik et al. ${ }^{18}$ Cerasmart showed the highest TP value at $0.5 \mathrm{~mm}$ and $1 \mathrm{~mm}$ thicknesses when compared with Lava Ultimate (3M, ESPE, USA) and Vita Enamic (VITA Zahnfabrik, Bad
Säckingen, Germany) besides the researchers recommended the use of Cerasmart material in anterior region. Gunal et al. ${ }^{19}$ compared the TP values of different CAD-CAM materials. They found the higher TP value for nano-ceramic composite resin, Cerasmart, than other hybrid-ceramics. Cerasmart does not contain $\mathrm{Al}_{2} \mathrm{O}_{3}$ like the hybrid-ceramic Vita Enamic or zirconia/silica nanoclusters like the resin nano-ceramic Lava Ultimate. Therefore, the difference in content might be the reason for the higher $\mathrm{TP}$ value of Cerasmart. Although crystalline content in ceramic materials improves the mechanical properties, it decreases the translucency. Stawarczyk et al. ${ }^{20}$ found 
statistically higher TP value for Cerasmart than IPS Empress CAD, which is a leucite reinforced glass ceramic block. To the best of the authors' knowledge, there was not a study which evaluated the LRF. Therefore, the results of the present study were compared with the results of the study of Stawarczyk et $a .^{20}$ whom evaluated the leucite reinforced glassceramic (IPS Empress CAD) which was comparable to LRF. Similarly, in the present study, the mean TP value of CER group (16.9 \pm 1.5$)$ was statistically higher than the mean TP value of LRF group $(14.1 \pm 0.5)$ in terms of baseline measurements $(p=0.013)$. Leucite crystals might be the reason decreasing the translucency of the LRF group.

Mechanical polishing and glazing are the surface finishing methods for the ceramic materials. However, hybrid-ceramic materials are not convenient for glazing procedure in a furnace with high temperatures because of their resin content. ${ }^{10}$ Therefore, in the present study only mechanical polishing technique was used for the hybrid-ceramic CAD-CAM block, Cerasmart. Kilınç et $a .^{21}$ revealed that polishing methods affect the color parameters of CAD-CAM materials. Awad et al. ${ }^{22}$ studied TP of different restorative materials and revealed that not only the thickness of the material but also the polished or rough surfaces would affect the results. In the present study, mechanical polishing did not affect the TP values in the CER (16.2 \pm 1.0$)$ and LRF $(14.6 \pm 0.7)$ groups significantly $(p>0.05)$. The mean TP value of the CER group was statistically higher than the mean TP value of the LRF group after mechanical polishing measurement $(p<0.001)$. One of the most important factors that affected the translucency was roughness. After mechanical polishing, the surface of the both materials became smoother which increased the translucency.

It is important for a clinician to know the response of a restorative material's translucency when subjected to coffee. Buyukkaplan et al. ${ }^{25}$ investigated the effect of coffee immersion for 28 days and found statistically no change in the translucency of hybrid-ceramic VITA Enamic blocks that were at two different translucency levels (VITA Enamic, 2M2 high translucent and translucent). These results were consistent with the present study. After coffee storage, TP values of CER and LRF groups did not change significantly and no significant difference was also found between the CER and LRF groups in terms of TP value $(p>0.05)$. However, in the present study, coffee storage caused staining, which might be the reason of decreasing TP of both materials.

The prophylactic paste is used to eliminate the plaque accumulation on the tooth. According to the previous studies, polishing with prophylactic paste resulted in a color change and influenced the surface roughness or translucency. ${ }^{20,23,27}$ Polishing with a prophylactic paste improves the properties by both smoothen surfaces and removing discolorations. ${ }^{11}$ In this regard, the duration of the polishing and the hand-piece speed are important factors. ${ }^{28}$ Therefore, in the present study, a fine grit prophylactic paste was used at 10,000 rpm for $1 \mathrm{~min}$. Ilie et al. $^{29}$ revealed that crystalline structure, size of grains, the number of defects, and porosity presence affect translucency. Results could be attributed to the chemical composition of CAD-CAM blocks that might influence the TP. In the present study, the mean TP values for both groups (CER group, 15.7 \pm 1.6 ; LFR group, 14.4 \pm 1.1 ) were increased after polishing with prophylactic paste. However, the difference of TP value between coffee storage and polishing with prophylactic paste was not statistically significant for both groups $(p>0.05)$. Removing the stain from surface might increase the translucency. Although, Monoca et al. ${ }^{28}$ studied translucency of IPS e.max CAD lithium disilicate ceramic and found that prophylactic pastes caused lowering in translucency which they related to loss of glaze layer.

The $\Delta \mathrm{E}_{00}<2.25$ is the threshold of clinically acceptable color difference and $\Delta \mathrm{E}_{00}<1.30$ is the threshold of the perceptibility of color difference. ${ }^{8,22}$ After mechanical polishing, $\Delta \mathrm{E}$ values of CER $(0.9 \pm 0.8)$ and LRF $(0.3 \pm 0.07)$ groups were below 1.30. After mechanical polishing, $\Delta \mathrm{E}$ value of the CER group was higher than $\triangle \mathrm{E}$ value of the LRF group; however, this difference was not statistically different $(p>0.05)$.

The discoloration of CAD-CAM materials may be observed after coffee storage. ${ }^{3,9,10,23}$ Acar et al. ${ }^{6}$ investigated color change concerning thermal cycling in coffee and revealed that color change of the hybridceramic (VITA Enamic), was perceivable but clinically acceptable and the color change of the lithium disilicate ceramic (IPS e.max CAD; Ivoclar Vivadent, Amherst, NY) was no perceivable. Barutcugil et al. ${ }^{3}$ investigated three types of CAD-CAM blocks (Lava Ultimate, Cerasmart, VITA Enamic), immersed the specimens in staining solutions for 1 month and found that the color change values were higher than the clinically acceptable values (specifically red wine followed by coffee).

Storage media also plays a considerable part in discoloration values. $^{20}$ In the present study, the specimens were stored in a coffee solution for one-week which corresponded to 7 months approximately since a study reported that 24 hours of exposure to drinks in vitro corresponds to 1 month in vivo. ${ }^{24}$

Correlatively, the results of the present study confirmed that coffee may change the color. $\Delta \mathrm{E}$ values

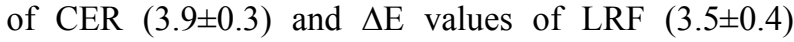
groups were higher than the 2.25 , clinically acceptable threshold level, and significantly higher than the $\Delta \mathrm{E}$ values obtained after mechanical polishing $(p<0.001)$. However, $\triangle \mathrm{E}$ values of the CER group were significantly higher than $\Delta \mathrm{E}$ values of the LRF group $(p=0.013)$. Similar to this study, Stawarczyk et al. ${ }^{20}$ 
revealed that hybrid-ceramics showed higher discoloration than the leucite reinforced feldspar ceramic regardless of the storage medium. Kurt et al. ${ }^{26}$ studied the optical properties of Cerasmart, Vita Enamic and Vita Suprinity (Vita Zahnfabrik Bad Säckingen, Germany) CAD-CAM blocks after thermal cycling and revealed that Cerasmart which has the highest resin matrix, showed more color change while the least color change was observed in Vita Suprinity, which does not contain any resin matrix. In general, as the amount of resin matrix in the material increases, and the lower amount of filler particles present the possibility of color change increases. ${ }^{11}$ The CER used in this study comprises a polymeric matrix reinforced by nano-hybrid fillers and therefore, be considered as a composite resins block. So, the reason for the higher discoloration rate of the CER group may be explained by the resin content.

$\Delta \mathrm{E}$ values of CER $(1.4 \pm 0.2)$ and LRF $(0.4 \pm 0.04)$ groups after polishing with prophylactic paste were significantly lower than the values after coffee storage $(p<0.001)$. Moreover, $\Delta \mathrm{E}$ values after polishing with prophylactic paste were below the 2.25 threshold of clinically acceptable color difference which indicated that prophylactic paste may be a choice to eliminate the discoloration of ceramic materials. $\Delta \mathrm{E}$ values of the CER group were significantly higher than $\Delta \mathrm{E}$ values of the LRF group $(p<0.001)$, which was indicated that removal of discoloration was easier in the LRF group than the CER group. This could be related to the homogeneous and dense structure of leucite crystals which improves the polishability. ${ }^{2}$

\section{REFERENCES}

1. Yu B, Ahn J-S and Lee Y-K. Measurement of translucency of tooth enamel and dentin. Acta Odontol Scand 2009;67:57-64.

2. https://europe.gc.dental/en-GB (2020, accessed 12 October, 2020).

3. Barutçugil Ç, Bilgili $\mathrm{D}$, Barutcigil $\mathrm{K}$, et al. Discoloration and translucency changes of CADCAM materials after exposure to beverages. J Prosthet Dent 2019;122:325-331.

4. Aladag A, Oguz D, Çömlekoglu ME, Akan E. In vivo wear determination of novel CAD/CAM ceramic crowns by using $3 \mathrm{D}$ alignment. J Adv Prothodont 2019;11:120-127.

5. Awada A and Nathanson D. Mechanical properties of resin-ceramic CAD-CAM restorative materials. J Prosthet Dent 2015;114:587-593.

6. Acar O, Yilmaz B, Altintas SH, et al. Color stainability of CAD-CAM and nanocomposite resin materials. J Prosthet Dent 2016;115:71-75.

7. Lauvahutanon S, Shiozawa M, Takahashi $\mathrm{H}$, et al. Discoloration of various CAD-CAM blocks after immersion in coffee. Restor Dent Endod 2017;42:918.
One of the limitations of the present study was that in-vitro studies cannot mimic the intraoral conditions. Another limitation was that a low speed cutting device, as used in the previous researches ${ }^{3,11,21,25}$ instead of a CAD-CAM system to obtain the specimens. Therefore, both in vitro and in vivo future studies are needed to evaluate more optical parameters of the CAD-CAM materials like gloss and surface roughness.

\section{CONCLUSION}

1. The optical properties of both CAD-CAM materials were material depended and may change over time by staining.

2. Hybrid-ceramic, Cerasmart, showed higher discoloration rate in coffee than leucite reinforced feldspar CAD-CAM ceramic, Initial LRF; although all of the materials exhibited unacceptable color change values.

3. Polishing with a prophylactic paste seems to be a good choice for both materials and it can be recommended in terms of color stability for the survival of restorations.

4. Cerasmart was found to be more translucent than Initial LRF for baseline and after all procedures.

\section{Acknowledgments}

The authors would like to thank GC Corporation, Tokyo, Japan for providing the materials.

Conflicts of Interest statement: None.

8. Abu-Obaid A, AlMawash A, Alyabis N, et al. An in vitro evaluation of the effect of polishing on the stainability of different CAD-CAM ceramic materials. Saudi Dent J 2019;32:135-141.

9. Sarikaya I, Yerliyurt K and Hayran Y. Effect of surface finishing on the colour stability and translucency of dental ceramics. BMC Oral Health 2018;18:40.

10. Sagsoz O and Sagsoz NP. Chemical degradation of dental CAD-CAM materials. Biomed Mater Eng 2019;30:419-426.

11. Liebermann A, Spintzyk S, Reymus M, et al. Nine prophylactic polishing pastes: impact on discoloration, gloss, and surface properties of a CAD-CAM resin composite. Clin Oral Investig 2019;23:327-335.

12. Commission Internationale de l'Eclairage (CIE). CIE technical report: colorimetry. [CIE Pub No.15.3]. 2004.

13. Johnston WM. Review of translucency determinations and applications to dental materials. JERD 2014;26:217-223. 
14. Yildirim B, Recen D, Tekeli Simsek A. Effect of cement color and tooth-shaded background on the final color of lithium disilicate and zirconiareinforced lithium silicate ceramics: An in vitro study. JERD 2020. (Epub ahead of the print)

15. Chu FC, Chow TW and Chai J. Contrast ratios and masking ability of three types of ceramic veneers. J Prosthet Dent 2007;98:359-364.

16. Tekce N, Tuncer S, Demirci M, et al. The effect of different drinks on the color stability of different restorative materials after one month. Restor Dent Endod 2015;40:255-261.

17. Koroglu A, Sahin O, Dede DO, et al. Effect of different surface treatment methods on the surface roughness and color stability of interim prosthodontic materials. J Prosthet Dent 2016;115:447-455.

18. Celik E and Goktepe B. Optical Properties of Novel Resin Matrix Ceramic Systems at Different Thicknesses. Cumhuriyet Dental Journal 209;22:176-184.

19. Gunal B and Ulusoy MM. Optical properties of contemporary monolithic CAD-CAM restorative materials at different thicknesses. JERD 2018;30:434-441.

20. Stawarczyk B, Sener B, Trottmann A, et al. Discoloration of manually fabricated resins and industrially fabricated CAD-CAM blocks versus glass-ceramic: effect of storage media, duration, and subsequent polishing. Dent Mater J 2012;31:377-383.

21. Kilinc $\mathrm{H}$ and Turgut $\mathrm{S}$. Optical behaviors of esthetic CAD-CAM restorations after different surface finishing and polishing procedures and UV aging: An in vitro study. J Prosthet Dent 2018;120:107-113.
22. Awad D, Stawarczyk B, Liebermann A, et al. Translucency of esthetic dental restorative CADCAM materials and composite resins with respect to thickness and surface roughness. J Prosthet Dent 2015;113:534-540.

23. Quek S, Yap A, Rosa V, et al. Effect of staining beverages on color and translucency of CAD-CAM composites. JERD 2018;30:9-17.

24. Ardu S, Braut V, Gutemberg D, et al. A long-term laboratory test on staining susceptibility of esthetic composite resin materials. Quintessence Int 2010;41:695-702.

25. Buyukkaplan SU, OMM, Barutcugil C, et al. Effects of staining liquids and finishing methods on translucency of a hybrid ceramic material having two different translucency levels. J Adv Prosthodont 2017;9:387-393.

26. Ayşegul K and Çelik G. Evaluation of physical and optical properties of hybrid CAD-CAM materials. Journal of the Dental Faculty of Ataturk University 2017;2017(2017)

27. Yurdaguven H, Aykor A, Ozel E, et al. Influence of a prophylaxis paste on surface roughness of different composites, porcelain, enamel and dentin surfaces. Eur J Dent 2012;6:1-8.

28. Monaco C, Arena A and Ozcan M. Effect of prophylactic polishing pastes on roughness and translucency of lithium disilicate ceramic. Int J Periodontics Restorative Dent 2014;34:26-29.

29. Ilie N and Hickel R. Correlation between ceramics translucency and polymerization efficiency through ceramics. Dent Mater 2008;24:908-914. 